\title{
Investigation of eGovernment Services and Alignment between Business and Information Systems
}

\author{
Sulaiman Abdulaziz Alfadhel \\ Plymouth Graduate School of \\ Management, Plymouth University \\ Plymouth, UK \\ Sulaiman.alfadhel@plymouth.a \\ c.uk
}

\author{
Festus O. Oderanti \\ Hertfordshire Business School, \\ University of Hertfordshire \\ Hatfield, UK \\ F.Oderanti@Herts.ac.uk
}

\begin{abstract}
Inhabitant's implementation of eGovernment services is a key objective for the Government of developed and developing countries. However, to improve the eGovernment services it is important for any Government to align all stakeholders so that the needs of citizens can be examined and addressed. This paper proposed a framework of an ideal pattern of alignment for the Government of Saudi Arabia. The framework has been validated empirically and the result indicates that the Government of Saudi Arabia is spending a huge amount of budget to improve the Government services, but still many services are slow and are not as per expectations. Therefore, citizens of KSA recommended alignment between eGovernment agencies and IS department.
\end{abstract}

\section{CCS Concepts}

- Social and professional topics $\rightarrow$ Management of computing and information systems $\rightarrow$ Professional topics $\rightarrow$ Management of computing and information systems $\rightarrow$ Implementation management $\bullet$ Social and professional topics $\rightarrow$ Management of computing and information systems $\rightarrow$ Professional topics $\rightarrow$ Management of computing and information systems $\rightarrow$ Software management

\section{Keywords}

e-Government; Alignment; MIS; e-Services; customer satisfaction; ideal pattern; Economic Systems; Technology Transactions

\section{INTRODUCTION}

The term eGovernment often refer to the communication between the Government and their Citizens (G2C) and where the Government tries to provide eGovernment service to their citizens. The Organization for Economic Co-operation and Development (OECD) defines eGovernment as "The use of Information Technology, mainly the Internet, as a tool to attain better government services" [12-14, 18]. An eGovernment offers products and services to those within its Governance and they manage those products and services electronically [16-18]. These products and services vary based on the customers' requirements and this diversity has given upsurge to the growth of several types of eGovernment. Carter and Belanger (2005) categorized

SAMPLE: Permission to make digital or hard copies of all or part of this work for personal or classroom use is granted without fee provided that copies are not made or distributed for profit or commercial advantage and that copies bear this notice and the full citation on the first page. To copy otherwise, or republish, to post on servers or to redistribute to lists, requires prior specific permission and/or a fee.

Conference'10, Month 1-2, 2010, City, State, Country.

Copyright 2010 ACM 1-58113-000-0/00/0010 _..\$15.00.

DOI: http://dx.doi.org/10.1145/12345.67890
eGovernment into four types: Government to Business (G2B), Government to Citizen (G2C), Government to Government (G2G) and Government to Employees (G2E).

In the context of the Kingdom of Saudi Arabia (KSA) projects related to the eGovernment have been identified as one of the priority areas of the government. However, the development and adoption of eGovernment sector are facing several challenges related to services quality and on-time delivery and this is because of the barriers including alignment between Government agencies and information technology sector, eGovernment structure, culture and social, organizational that must be considered and analyzed carefully.

The key challenge of eGovernment in KSA is non-alignment between Government agencies and Information Systems, this led to the poor quality of eGovernment services and lack of Government trust among the public [19-23]. This paper proposed an ideal pattern of alignment for the KSA Government. An ideal pattern of alignment consists of four types of alignment, namely: strategic alignment between Government agencies and IS, structural alignment between Government agencies and IS, social alignment between Government agencies and IS and cultural alignment between Government agencies and IS.

\section{METHODOLOGY}

This section presents details of the survey. Data cleaning and screening were an important stage for this study, as the data analysis process might have been influenced and impact the study outcomes, for example, if there are missing value and data inconsistency which has not been checked. For this study, it was essential to alter the text responses for question 3 "Please specify eGovernment services you use?" to numeric values, the question asks about eGovernment services participants uses, such as eHealth, eTax, student loan, Family tax benefits, and Interior Ministry e-services and then to determine missing data, every factor were exposed to frequency examinations. This resulted in 56 responses revealing missing data, therefore, these 56 responses were not included in the study and 200 responses were further filtered to identify respondents who never use eGovernment services before.

\section{RESULT AND DISCUSSION}

This study discussed the ideal pattern of alignment in the context of eGovernment services in the KSA region. There have been four patterns of alignment and where each pattern included sub-factors of the domain. This section discusses the data analysis result.

\subsection{Demographic Profile}


Paper presented at the ICEEG 3rd International Conference on E-commerce, E-Business and E-Government, 18/06/19 - 21/06/19,

Lyon, France.

The demographic profile was constructed in the first question of the survey which indicated the study participants location in the KSA. Table 1 indicates that the survey response was from 11 cities of KSA. From 200 responses, $10 \%$ participants were from the city of Riyadh, $10.50 \%$ participants were from the city of Jeddah, $10 \%$ participants were from the city of Mecca, $10 \%$ participants were from the city of Medina, $12.50 \%$ participants were from the city of Buraidah, $10.50 \%$ participants were from the city of Dammam, $12.50 \%$ participants were from the city of Tabuk, $6 \%$ participants were from the city of khobar, $7.50 \%$ participants were from the city of Unzizah, $10 \%$ participants were from the city of Taif, and $0.50 \%$ other cities ok the KSA.

Table 1. Responded city of residency

\begin{tabular}{|l|r|r|r|r|}
\hline \multicolumn{5}{|c|}{ Participants city of residence } \\
\hline City & Frequency & Percent & $\begin{array}{c}\text { Valid } \\
\text { Percent }\end{array}$ & $\begin{array}{c}\text { Cumulative } \\
\text { Percent }\end{array}$ \\
\hline Buraidah & 25 & 12.5 & 12.5 & 12.5 \\
\cline { 2 - 5 } Dammam & 21 & 10.5 & 10.5 & 23.0 \\
\cline { 2 - 5 } Jeddah & 21 & 10.5 & 10.5 & 33.5 \\
\cline { 2 - 5 } khobar & 12 & 6.0 & 6.0 & 39.5 \\
\cline { 2 - 5 } Mecca & 20 & 10.0 & 10.0 & 49.5 \\
\cline { 2 - 5 } Medina & 20 & 10.0 & 10.0 & 59.5 \\
\cline { 2 - 5 } other & 1 & .5 & .5 & 60.0 \\
\cline { 2 - 5 } Riyadh & 20 & 10.0 & 10.0 & 70.0 \\
\cline { 2 - 5 } Tabuk & 25 & 12.5 & 12.5 & 82.5 \\
\cline { 2 - 5 } Unif & 15 & 10.0 & 10.0 & 92.5 \\
\cline { 2 - 5 } Total & 200 & 100.0 & 100.0 & 100.0 \\
\cline { 2 - 5 } & 20.5 & 7.5 & \\
\cline { 2 - 5 } & & & \multicolumn{3}{|c}{} \\
\hline
\end{tabular}

This result indicates that the Government of Saudi Arabia is more aware of eGovernment users in the larger cities as compared to the smaller cities. This is why, more eGovernment users participate in this study from the larger cities like Riyadh, Jeddah, Mecca, Medina, Buraidah, Dammam, and Tabuk. Only a few users participated from the smaller cities like khobar, Unzizah, and Taif.

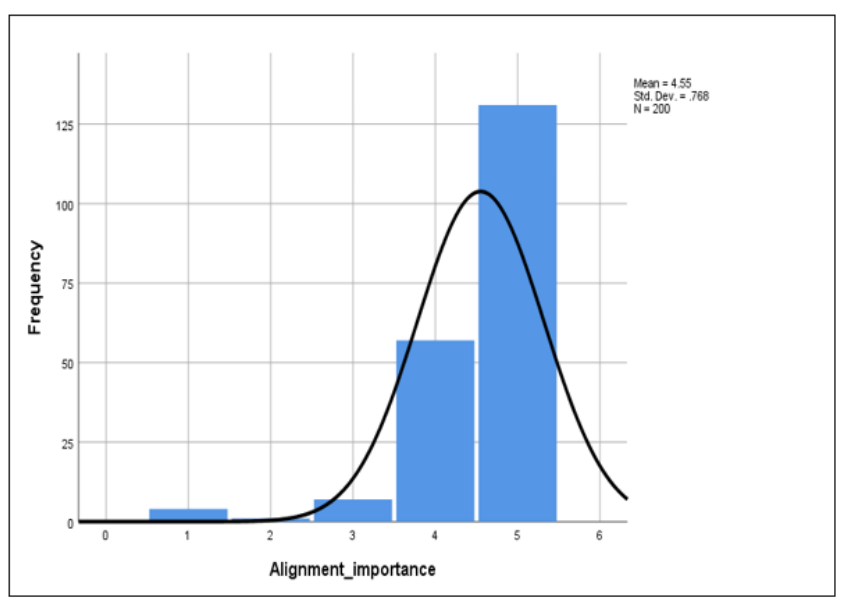

Figure 1. eGovernment users about alignment importance.

To develop an understanding of alignment and eGovernment acceptance and its importance from this study. In the second question in the survey questionnaire, participants were asked eGovernment users about the importance of alignment between Government agencies and IS department and how this alignment is important for the eGovernment sector in KSA. Figure 1 indicates that out of 200 participants, $65.5 \%$ participants "Strongly agreed" that alignment is the only solution for the quality of eGovernment services, $28.5 \%$ participants "Agreed" on the alignment importance, $3 \%$ participants chosen "Neutral", $1 \%$ participant "Disagree" and 2\% participants think alignment is not important at all and they chose "Strongly disagree".

\subsection{Alignment Patterns Reliability}

Four patterns of alignment in the context of eGovernment has been identified from the literature and sub-factors in each alignment pattern has been identified and validated among eGovernment experts. This section presents the evaluation of each alignment pattern and their sub-factors among eGovernment users in KSA.

The quantitative method in the eGovernment sector requires that instruments are assessed in relation to the reliability and validity, therefore that the collected data requires details evaluation to understand any possible insufficiency and to overcome any possible errors, thus the investigator can be assured about the measurement of accuracy. According to Hair et al. (2006), and Field (2013) reliability testing refers to "whether a data could be understood continually across different circumstances. In this case, reliability can be defined as measuring an idea steadily, so that investigation discoveries would be verified if the data result was repeated. Bryman (2008) define two terms of reliability: the first form of reliability ensures the measure endured stable with the passage of time and never fluctuate. Second, internal reliability defines to check whether the scale indicators were steady [6]. This form of the reliability of is used to measure by splitting the study data into two splits, and the participant's scores are considered for every half, and then check with the statistical correlation.

Table 2. Cronbach's Alpha for the model constructs

\begin{tabular}{|r|r|r|}
\hline \multicolumn{2}{|c|}{ Reliability Statistics for constructs } \\
\hline Model constructs & Cronbach's Alpha & N of Items \\
\hline Alignment pattern 1: Strategic & 0.701 & 5 \\
\hline Alignment pattern 2: Structure & 0.713. & 5 \\
\hline Alignment pattern 3: Social & 0.691 & 4 \\
\hline Alignment pattern 4: Cultural & 0.711 & 5 \\
\hline
\end{tabular}

This study employed the Cronbach alpha test to measure inner reliability, Table 2 demonstrates Cronbach's alpha values for the involved ideal patterns of alignment for each pattern or for each construct. The results show the reliability of the scale indicators, consistency of the study data and homogeneity of the ideal pattern of alignment.

\subsection{Factor Analysis (Ideal Pattern of Alignment Pattern eGovernment)}

An eGovernment means the use of information and communication technologies in order to recover the activities of citizens and publicsector organizations. There are three key domains of eGovernment, namely: improving eGovernment activities and processes, connecting citizens and building external interactions. Therefore, factor analysis is important, and this research implements CFA for the model fit and several tests in statistics used to determine how the proposed model fit to the study data Bryman (2008).

MacCallum et al. (1996) suggested that sample-size requirements for the RMSEA goodness of fit by means of effect size and model degrees of freedom. A structural equation model was evaluated and tested to examine the study hypothesis that identification of the ideal pattern of alignment and satisfaction of KSA eGovernment 
Paper presented at the ICEEG 3rd International Conference on E-commerce, E-Business and E-Government, 18/06/19 - 21/06/19, Lyon, France.

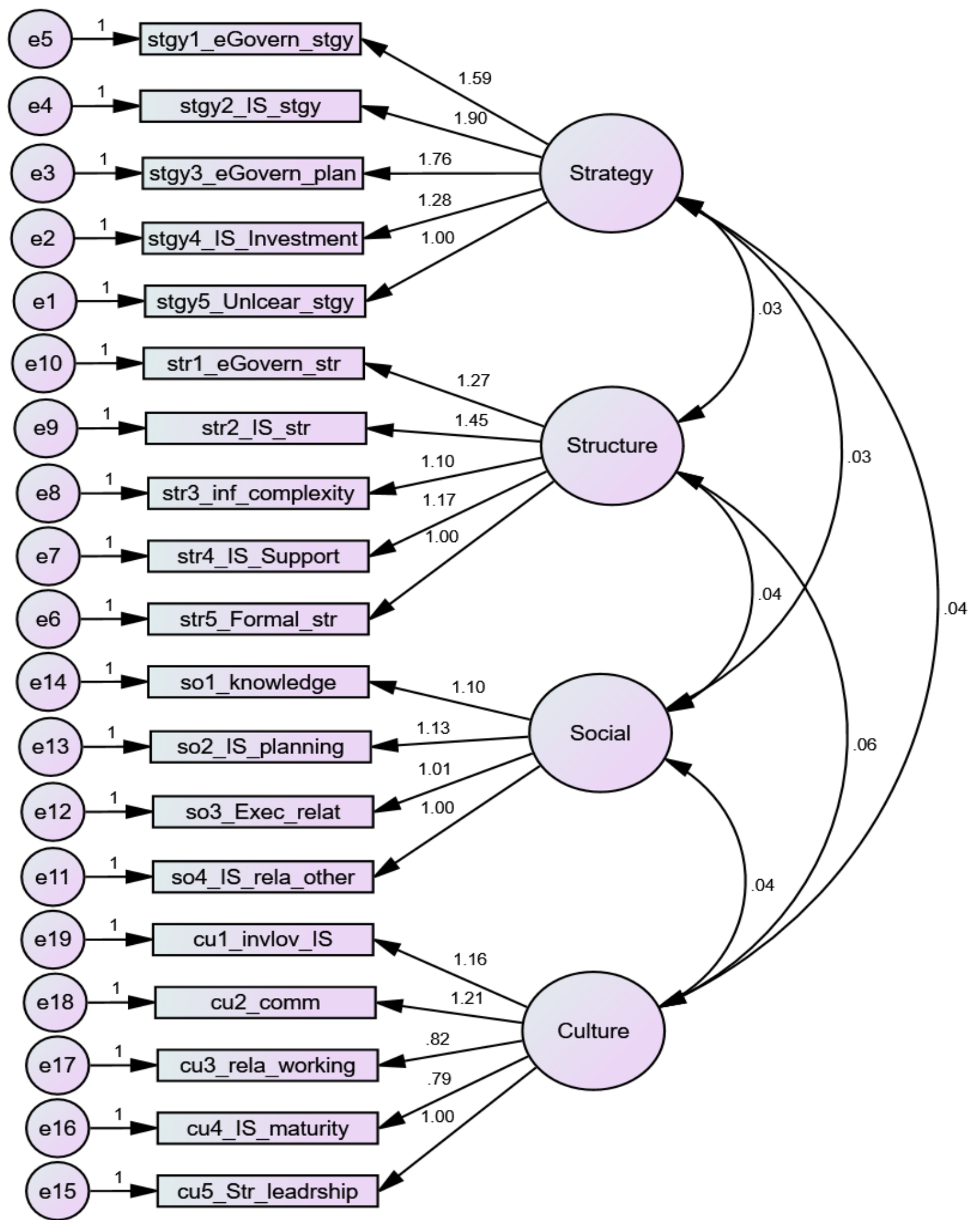

user about their services. Both ideal pattern and eGovernment services satisfaction were latent variables in this proposed model.

The factors analysis result our model fit are as follows: CMIN $=5.098, \quad$ GFI $=0.910, \quad$ CFI $=0.988, \quad$ PCLOSE $=0.504 \quad$ and RMSEA $=0.03$. this result indicates that our model is fit with the study hypothesis and the planned model. SEM is a multivariate arithmetical analysis method that is employed to analyze structural relationships for the proposed research. This method is the mixture of multiple regression analysis and factor analysis and it is employed to analyze the structural relationship among latent constructs and measured variables. This method is favored by the investigator because it evaluates the interrelated and multiple dependence in just one form of analysis. In this research, we have applied the SEM and model presented in figure 2. The model in figure 2 indicates that all four pattern and their sub-factors are strongly correlated. Therefore, Government of KSA should implement the complete pattern of alignment in order to improve the eGovernment services. 
Paper presented at the ICEEG 3rd International Conference on E-commerce, E-Business and E-Government, 18/06/19 - 21/06/19, Lyon, France.

Figure 2. Structural equation model.

\subsection{Factor Analysis Through Pattern Matrix}

For the validation of any research hypothesis or a framework, it is important to identify the relationship of sub factors with their parent factor and sub-factor loading on their parent factor. Any all subfactors load on their perspective parent factor, it means they are strongly aligned and statistically the proposed framework is valid. According to Bryant and Yarnold (1995) the term factor rotation is a procedure, where sub-factors are rotated in an attempt to attain simple structure [7]. For this research, we have used varimax rotation in order to maximize the association among sub-factors and their perspective parent factor [8].

The rotated alignment pattern (parent factor) and how groups of sub-factors in one alignment pattern are loaded on their perspective parent factor is shown in Table 3. The result of pattern matric indicates that all sub-factors are nicely loaded on their related parent factor and very clean factor structure presented in table 3. A strategic alignment factor included five sub-factors: "eGovernment strategy must be aligned with IS strategy", "IS strategy must be aligned with eGovernment strategy", "eGovernment plan must be aligned with IS plan", "eGovernment must consider IS as assert not tool" and "invest enough in IS and eGovernment strategy unclear among IS staff and vice versa". All five sub-factors loaded on strategic alignment factor, which indicate, all five sub-factors are belonged to the strategic alignment and have zero correlation with other alignment patterns.

Table 3. Alignment factors loading

\begin{tabular}{|c|c|c|c|c|}
\hline \multicolumn{5}{|c|}{ Pattern Matrix } \\
\hline & \multicolumn{4}{|c|}{ Factor } \\
\hline & 1 & 2 & 3 & 4 \\
\hline \multicolumn{5}{|l|}{ Strategic Alignment } \\
\hline stgy1_eGovern_stgy & .583 & & & \\
\hline stgy2_IS_stgy & .552 & & & \\
\hline stgy3_eGovern_plan & .526 & & & \\
\hline stgy4_IS_Investment & .468 & & & \\
\hline stgy5_Unlcear_stgy & .658 & & & \\
\hline \multicolumn{5}{|l|}{ Structural Alignment } \\
\hline str1_eGovern_str & & .494 & & \\
\hline str2_IS_str & & .597 & & \\
\hline str3_inf_complexity & & .365 & & \\
\hline str4_IS_Support & & .722 & & \\
\hline str5_Formal_str & & .502 & & \\
\hline \multicolumn{5}{|l|}{ Social Alignment } \\
\hline so1_knowledge & & & .837 & \\
\hline so2_IS_planning & & & .665 & \\
\hline so3_Exec_relat & & & .522 & \\
\hline so4_IS_rela_other & & & 712 & \\
\hline \multicolumn{5}{|l|}{ Cultural Alignment } \\
\hline cu1_invlov_IS & & & & .983 \\
\hline cu2_comm & & & & .552 \\
\hline cu3_rela_working & & & & .626 \\
\hline cu4_IS_maturity & & & & .868 \\
\hline cu5_Str_leadrship & & & & .558 \\
\hline
\end{tabular}

A structural alignment factor included five sub-factor: "eGovernment structure flexible to support alignment with IS", "IS department structure should have suitable resources to support eGovernment goal", "Complex eGovernment structure could lead to non-alignment", "Lack of IS department support or investment could lead to non-alignment" and "eGovernment formal structure could lead to a lack of technological support from IS department". All five sub-factors loaded on structural alignment factor, which indicates, all five sub-factors that belong to the structural alignment pattern and has zero correlation with other alignment patterns.

Third group of alignment was a social alignment which included four sub-factor: "IS department and other eGovernment agencies should share domain knowledge for the stronger alignment between both", "IS department planning must align with eGovernment planning so that IS support Government goals", "CEOs and CIO from IS department should have long term relationships and planning so that alignment can be achieved", and "Strong alignment required close relationship between IS department staff and staff from other Government agencies". All four sub-factors loaded on social alignment factor, which indicate, all five subfactors are belonged to the social alignment and have zero correlation with other alignment patterns.

The fourth group of alignment was a cultural alignment which included five sub-factor: "eGovernment top management should involve in IS planning that support cultural alignment", "Better communication between IS department and other agencies in the eGovernment could improve alignment between both", "Strong working relationship between IS department and other agencies help to improve cultural alignment", "IS department should culturally mature to support Government goals", and "Effective and helpful leadership of the IS department and other agencies in the eGovernment could improve cultural alignment in the Government infrastructure". All five sub-factors loaded on cultural alignment factor, which indicate, all five sub-factors are belonged to the cultural alignment and have zero correlation with other alignment patterns.

This study result indicates, the IS department in eGovernment sector should receive the same attention as other areas of eGovernment and also it would be discussed with the same position as well. In KSA IS department is seen as a distinct component of the eGovernment that required to be affiliated with the eGovernment goals and numerous other KSA Government sectors still operate this way. Therefore, the IS department in KSA must be seen as an essential element of eGovernment of KSA, not a distinct department. After all, the IS department permits eGovernment in KSA capabilities and is an area of eGovernment strategic benefit for Government.

\section{CONCLUSION}

The paper presents and analyses the quantitative survey data that reveals the ideal pattern of alignment in the context of eGovernment services adoption. Moreover, the paper also presents the analysis of satisfaction of eGovernment users about the eservices that KSA providing. This paper began with a basic analysis to evaluate the consistency of study data by finding the outliers, missing value and the expectations of the normal distribution. 
Paper presented at the ICEEG 3rd International Conference on E-commerce, E-Business and E-Government, 18/06/19 - 21/06/19,

Lyon, France.

Study result revealed that Government of KSA is currently spending huge amount of budget on the development of new eGovernment services and spending on improving the existing services. However, still many Government services are not online, therefore, KSA citizens highly recommend strong alignment between eGovernment agencies and IS department. In the survey, we asked participants to rank the importance of alignment and confirm the factors that should lead to strong alignment. Data result shows that eGovernment user in KSA is agreed to have an ideal pattern of alignment, which aligned the eGovernment environment strategical, structural, social and culturally. This strong alignment alternately will improve the quality of eGovernment service in the country.

\section{REFERENCES}

[1] MacCallum, R. C., Browne, M. W., and Sugawara, H. M. 1996. Power analysis and determination of sample size for covariance structure modeling. Psychological Methods, 1, 130-149.

[2] Carter, L. and Bélanger, F., 2005. The utilization of e government services: citizen trust, innovation and acceptance factors. Information systems journal, 15(1), pp.5-25.

[3] Field, A., 2013. Discovering statistics using IBM SPSS statistics. sage.

[4] Tabachnick, B. G., and Fidell, L. S. 2007. Using multivariate statistics (5th ed.). Boston: Allyn and Bacon.

[5] Hair, J. F., Black, W. C., Babin, B. J., Anderson, R. E. and Tatham, R. L. 2006. Multivariate data analysis. Vol. 6..

[6] Bryman, A. 2008. Social research methods (3rd ed.), Oxford: Oxford University Press.

[7] Bryant, F. B. and Yarnold, P. R. 1995. Principal-components analysis and exploratory and confirmatory factor analysis.

[8] Gorsuch, R. L. 1983. Factor analysis (2nd Ed.). Hillsdale, NJ: Lawrence Erlbaum Associates.

[9] Marsh, H. W. and Hocevar, D., 1985. Application of confirmatory factor analysis to the study of self-concept: Firstand higher order factor models and their invariance across groups. Psychological bulletin, 97(3), p.562.

[10] Press, S. J., 1989. Bayesian statistics: principles, models, and applications, vol. 210. John Wiley \& Sons Inc.

[11] Press, S. J. 1989. Bayesian statistics: principles, models, and applications, vol. 210. John Wiley \& Sons Inc.

[12] Heeks, R. 2003. Most e-government-for-development projects fail: How can risks be reduced? vol. 14. Manchester: Institute for Development Policy and Management, University of Manchester.
[13] Heeks, R. and Bailur, S. 2007. Analyzing e-government research: Perspectives, philosophies, theories, methods, and practice. Government information quarterly, 24(2), 243-265.

[14] Vicente, M. and Sussy, B. 2018, April. Determining Aspects in the Development of Municipal e-Government. In 2018 International Conference on eDemocracy \& eGovernment (ICEDEG), 158-165. IEEE.

[15] Veeramootoo, N., Nunkoo, R. and Dwivedi, Y. K., 2018. What determines success of an e-government service? Validation of an integrative model of e-filing continuance usage.

[16] Garín-Muñoz, T., López, R., Pérez-Amaral, T., Herguera, I. and Valarezo, A. 2018. Models for individual adoption of eCommerce, eBanking and eGovernment in Spain. Telecommunications Policy.

[17] Liu, D. and Carter, L. 2018, May. Impact of citizens' privacy concerns on e-government adoption. In Proceedings of the 19th Annual International Conference on Digital Government Research: Governance in the Data Age (p. 27). ACM.

[18] Flores, A., Ramírez, S., Toasa, R., Vargas, J., UrvinaBarrionuevo, R. and Lavin, J.M. 2018, April. Performance Evaluation of NoSQL and SQL Queries in Response Time for the E-government. In 2018 International Conference on eDemocracy \& eGovernment (ICEDEG), 257-262. IEEE.

[19] Das, R. K. and Mishra, H. 2018, April. Smart E-Governance and Sustainable Development: Strategic Alignment Assessment Framework. In Proceedings of the 11th International Conference on Theory and Practice of Electronic Governance, 690-692. ACM.

[20] Othman, M. H. and Razali, R. 2018. Whole of Government Critical Success Factors towards Integrated E-Government Services: A Preliminary Review. Jurnal Pengurusan (UKM Journal of Management), 53.

[21] Ullah, A. and Lai, R., 2013. A systematic review of business and information technology alignment. ACM Transactions on Management Information Systems (TMIS), 4(1), 4.

[22] Ullah, A. and Lai, R. 2011. Modeling business goal for business/it alignment using requirements engineering. Journal of Computer Information Systems, 51(3), 21-28.

[23] Alahmadi, A. H., Soh, B. and Ullah, A. 2014. Improving eHealth services and system requirements by modelling the health environment. Journal of Software, 9(5), 1189-1202. 